\title{
Two exonic single nucleotide polymorphisms in the microsomal epoxide hydrolase gene are jointly associated with preeclampsia
}

\author{
Jaana Laasanen ${ }^{1}$, Eeva-Liisa Romppanen ${ }^{2}$, Mikko Hiltunen ${ }^{3,4}$, Seppo Helisalmi ${ }^{3,4}$, \\ Arto Mannermaa ${ }^{4}$, Kari Punnonen ${ }^{2}$ and Seppo Heinonen ${ }^{*, 1}$
}

\begin{abstract}
${ }^{1}$ Department of Obstetrics and Gynecology, Kuopio University and University Hospital, Kuopio, Finland; ${ }^{2}$ Department of Clinical Chemistry, Kuopio University and University Hospital, Kuopio, Finland; ${ }^{3}$ Department of Neuroscience and Neurology, Kuopio University and University Hospital, Kuopio, Finland; ${ }^{4}$ Department of Clinical Genetics, Kuopio University and University Hospital, Kuopio, Finland
\end{abstract}

This study determined whether genetic variability in exons 3 and 4 of the microsomal epoxide hydrolase gene jointly modifies individual preeclampsia risk. The study also determined whether genetic variability in the gene encoding for microsomal epoxide hydrolase (EPHX) contributes to individual differences in susceptibility to the development of preeclampsia. The study involved 133 preeclamptic and 115 healthy control pregnant women who were genotyped for two single nucleotide polymorphisms (SNPs), $\rightarrow C$ (Tyr113His) in exon 3 and $A \rightarrow G$ (His139Arg) in exon 4, in the $E P H X$ gene. Chi-square analysis was used to assess genotype and allele frequency differences between the preeclamptic and control groups. In addition, single-point analysis was expanded to pair of loci haplotype analysis to examine the estimated haplotype frequencies of the two SNPs, of unknown phase, among the preeclamptic and control groups. Estimated haplotype frequencies were assessed using the maximum-likelihood method, employing an expectation-maximization (EM) algorithm. Single-point allele and genotype distributions in exons 3 and 4 of the EPHX gene were not statistically different between the groups. However, according to the haplotype estimation analysis, we observed a significantly elevated frequency of haplotype T-A (Tyr113His 139) among the preeclampsia group vs the control group $(P=0.01)$. The odds ratio for preeclampsia associated with the high-activity haplotype T-A (Tyr113-His139) was 1.61 (95\% Cl: 1.12-2.32). The use of two intragenic SNPs jointly in haplotype analysis of association demonstrated that the genetically determined high-activity haplotype T-A (Tyr113-His139) was significantly associated with preeclampsia. European Journal of Human Genetics (2002) 10, 569-573. doi:10.1038/sj.ejhg.5200849

Keywords: preeclampsia; polymorphism; EPHX

\section{Introduction}

Microsomal epoxide hydrolase (EPHX) catalyses the phase I hydrolysis of epoxides, playing a role in detoxification processes and in the metabolism of endogenous and exogenous compounds. The gene is located in chromosomal region 1q42.1 and two single nucleotide

*Correspondence: S Heinonen, Department of Obstetrics and Gynecology, Kuopio University Hospital, 70211 Kuopio, Finland.

Tel: 358-17-172 325; Fax: 358-17-172 486;

E-mail: seppo.heinonen@kuh.fi

Received 27 February 2002; revised 1 May 2002; accepted 23 May 2002 polymorphisms (SNPs) have been described in the coding region of the EPHX1 gene that produce two protein variants. ${ }^{1}$ Hassett et al demonstrated in in vitro expression studies of cDNA that an exon $3 \mathrm{~T}$ to $\mathrm{C}$ mutation, that changes the tyrosine residue at codon 113 to histidine, decreased EPHX enzymatic activity by approximately $40 \%$, whereas a change of histidine to arginine at codon 139 of exon 4 decreased EPHX activity by approximately $25 \%{ }^{2}$ These polymorphisms are thought to be linked to protein stability. Zusterzeel et al described an association between the high activity genotype in exon 3 and preeclampsia. $^{3}$ 
The authors postulated that this genotype might be reflected in enhanced enzyme activation by either endogenous or exogenous substrates to result in more reactive mutagenic diol derivatives in these patients. Polymorphism in the EPHX gene may also have other roles in the reproductive system and modify the susceptibility to spontaneous abortion ${ }^{4}$ and ovarian cancer, ${ }^{5}$ the high activity genotype being associated with ovarian cancer and protection against spontaneous abortions. Again, mechanisms behind these observations are highly speculative but may be associated with alterations in steroid metabolism.

Taken together, these reports suggest that a role of EPHX in female reproduction and especially in the development of preeclampsia is plausible but not completely understood. The Finnish population is considered to be a genetic isolate, and thus ideal for genetic association studies. ${ }^{6}$ We designed a controlled study to test the possible association between two EPHX gene SNPs and preeclampsia to determine whether such an association exists across populations.

\section{Materials and methods}

Written approval for the study was obtained from the Ethics Committee of Kuopio University Hospital. Informed consent was obtained from all patients and the 115 controls, and documented.

Information was collected retrospectively in connection with 133 preeclamptic pregnancies of primiparous women and 115 control women with no history of preeclampsia who delivered at Kuopio University Hospital between January 1994 and December 1998. Using the Birth Registry at Kuopio, we sought preeclamptic patients, called them back, and at that time they were asked to sign an informed consent. During the same time, we collected blood samples from controls who had given birth in the same hospital after uncomplicated pregnancies and who had at least two normal pregnancies, including the current one. From controls, blood was drawn for DNA analysis at enrolment. To ensure homogeneity of the genetic background, the controls, originating from a regional population and with no clinical signs of the disorder, were enrolled by random selection in this case-control study.

Preeclampsia was defined as the development of hypertension and new-onset proteinuria (>300 mg of urinary protein in $24 \mathrm{~h}$ ) in women with no proteinuria at baseline. Hypertension was defined according to current guidelines that accept 140 and/or $90 \mathrm{mmHg}$ of systolic and diastolic pressure respectively, or higher, as hypertension, when measured on two consecutive occasions at least $24 \mathrm{~h}$ apart (Report of the National High Blood Pressure Education Program Working Group on High Blood Pressure in Pregnancy, 2000). ${ }^{7}$ Women with chronic hypertension were excluded from the study.

DNA was extracted from peripheral blood lymphocytes using a standard phenol-chloroform extraction method. Two sequence variants of the EPHX gene, a transition of $\mathrm{T}$ to $\mathrm{C}$ leading to the replacement of tyrosine by histidine (Tyr113His) in exon 3 and a transition of A to G leading to the replacement of histidine by arginine (His139Arg) in exon 4, were detected. The target DNA sequence in EPHX gene exon 3 was amplified using primers 5'-GGG GTC CTG AAT TTT GCT CC-3' and 5'-CAA TCT TAG TCT TGA AGT GAC GGT-3', and in EPHX gene exon 4 the primers used were 5'-TCT GGT GCC AGA GCC TGA CCG TGC-3' and 5'-ATG GAA CCT CTA GCA GCC CCG TAC C-3'. The incubation mixture contained $50 \mathrm{ng}$ of genomic DNA, 10 pmol of the amplification primers for exons 3 or 4 , $5 \mathrm{nmol}$ each of four deoxynucleotide triphosphates, $1 \mathrm{U}$ AmpliTaq Gold $^{\mathrm{TM}}$ DNA polymerase (Perkin Elmer), $10 \mathrm{~mm}$ Tris- $\mathrm{HCl}\left(\mathrm{pH} 8.3\right.$ at $\left.25^{\circ} \mathrm{C}\right), 50 \mathrm{mM} \mathrm{KCl}, 1.5 \mathrm{mM} \mathrm{MgCl}_{2}$ in a reaction volume of $25 \mu \mathrm{l}$. The cycling protocol included initial denaturation at $95^{\circ} \mathrm{C}$ for $7 \mathrm{~min}$, followed by a cycle of $95^{\circ} \mathrm{C}$ for $1 \mathrm{~min}, 55^{\circ} \mathrm{C}$ for $1 \mathrm{~min}$ (for exon 3) or $64^{\circ} \mathrm{C}$ for $1 \mathrm{~min}$ (for exon 4 ), and $72^{\circ} \mathrm{C}$ for $1 \mathrm{~min}$. A total of 35 cycles were carried out, with final extension at $72^{\circ} \mathrm{C}$ for $10 \mathrm{~min}$. For detection of the Tyr113His polymorphism, the PCR mixtures containing an amplified 198-bp DNA region were incubated with $5 \mathrm{U}$ of Tth 111 I enzyme (Promega), $1 \times$ Buffer B $\left(6 \mathrm{~mm}\right.$ Tris- $\mathrm{HCl}, \mathrm{pH} 7.5$ at $37^{\circ} \mathrm{C}, 50 \mathrm{~mm}$ $\mathrm{NaCl}, 6 \mathrm{mM} \mathrm{MgCl}_{2}, 1 \mathrm{~mm}$ dithiothreitol), and $1 \mu \mathrm{g}$ of acetylated bovine serum albumin in a total volume of $30 \mu \mathrm{l}$ for $2 \mathrm{~h}$ at $65^{\circ} \mathrm{C}$. The His139Arg polymorphism in exon 4 was detected by incubating the PCR mixtures containing a 322-bp PCR product with $5 \mathrm{U}$ RsaI enzyme (Promega), $1 \times$ Buffer C $\left(10 \mathrm{~mm}\right.$ Tris- $\mathrm{HCl}, \mathrm{pH} 7.9$ at $37^{\circ} \mathrm{C}, 50 \mathrm{~mm} \mathrm{NaCl}$, $10 \mathrm{mM} \mathrm{MgCl}, 1 \mathrm{~mm}$ dithiothreitol), and $1 \mu \mathrm{g}$ of acetylated bovine serum albumin in a total volume of $30 \mu \mathrm{l}$ for $2 \mathrm{~h}$ at $37^{\circ} \mathrm{C}$. The reaction mixtures were subjected to electrophoresis on 3\% agarose gels and photographed under an UV transilluminator after staining with ethidium bromide.

Two-tailed pooled $t$-tests were used to analyse continuous variables. Statistical analyses for comparing single-point allele and genotype frequencies were carried out using Pearson's $\chi^{2}$-test (two-sided asymptotic $P$ values), with SPSS 9.0 software. Odds ratios (ORs), as the estimates of relative risk of disease, were calculated using 95\% confidence intervals (CIs). We used an expectation-maximisation (EM) algorithm to obtain maximum-likelihood estimates of EPHX exon 3 and 4 haplotype frequencies with standard deviations (SD) (each haplotype consisting of a pair of SNPs, and unknown gametic phase; Arlequin ver. 2.000 software). Haplotype frequency comparisons between the preeclamptic and control groups with absolute chromosome numbers were carried out using Fisher's exact test (twosided $P$ values with Monte Carlo estimate at the $99 \%$ confidence level). Hardy-Weinberg distribution of genotypes in the preeclamptic and control groups, as well as pairwise linkage disequilibrium (LD) analyses, were assessed using Arlequin ver. 2.000 software. RxC program employing the Metropolis algorithm was used for analysis of contingency tables to obtain unbiased estimates of exact $P$ values with 
standard errors (SEs) in haplotype analyses. Power determinations were performed using nQuery Advisor Release 3.0 software. The level of statistical significance was defined as $P<0.05$.

\section{Results}

Clinical characteristics of preeclamptic women and controls are shown in Table 1. All preeclamptic women were nulliparas, whereas controls had two or more deliveries. However, in the control group the case records of their first pregnancies were also used for comparison to exclude the confounding effect of parity on pregnancy outcome. On average, deliveries occurred 5 weeks earlier in preeclamptic women than controls. The mean $( \pm$ standard deviation (SD)) gestational age at the development of preeclampsia was $31.7( \pm 3.5)$ weeks. There were no cases with HELLP syndrome. When only the first-degree relatives of the index patients were taken into account, a positive family history was reported in 30 affected women, who had six affected sisters and 28 affected mothers.

To determine whether the EPHX SNP loci at exon 3 $(\mathrm{T} \rightarrow \mathrm{C}$; Tyr113His) and exon $4(\mathrm{~A} \rightarrow \mathrm{G}$; His139Arg) were associated with preeclampsia, we initially compared the singlepoint genotype and allele distributions of these SNPs between preeclamptic and control groups (Table 2). Genotype and allele distributions of exons 3 and 4 SNPs did not reveal statistically significant single-point association with preeclampsia. However, the $\mathrm{T}$ allele of the exon 3 SNP (Tyr113) was over-represented among the preeclampsia group (0.74) when compared with the control group (0.66), displaying a borderline association with preeclampsia $(P=0.05$; OR 1.46 (95\% CI: $0.99-2.15)$ ). To study the above-mentioned borderline association result in terms of detection power, we estimated the possible number of subjects needed for a significant result with the exon 3 polymorphism, using simulation analysis. This analysis indicated that more than 150 patients and controls would have been needed at $80 \%$ power to show a significant

Table 1 Clinical characteristics

\begin{tabular}{|c|c|c|c|}
\hline Characteristic & $\begin{array}{l}\text { Preeclampsia } \\
(\mathrm{n}=133) \\
\text { Mean }(95 \% \mathrm{Cl})\end{array}$ & $\begin{array}{l}\text { Control } \\
(\mathrm{n}=115) \\
\text { Mean }(95 \% \mathrm{Cl})\end{array}$ & $\mathrm{P}$ \\
\hline Age (years) & $28.8(27.7-29.9)$ & $28.7(27.7-29.7)$ & 0.894 \\
\hline $\mathrm{BMI}\left(\mathrm{kg} / \mathrm{m}^{2}\right)$ & $24.9(24.0-25.7)$ & $22.3(21.6-23.0)$ & $<0.001$ \\
\hline $\begin{array}{l}\text { Systolic BP } \\
(\mathrm{mmHg})\end{array}$ & $161(158-164)$ & $131(128-134)$ & $<0.001$ \\
\hline $\begin{array}{l}\text { Diastolic BP } \\
(\mathrm{mmHg})\end{array}$ & $104(101-105)$ & $82(80-84)$ & $<0.001$ \\
\hline Birth weight (g) & $2285(2122-2448)$ & $3494(3408-3580)$ & $<0.01$ \\
\hline $\begin{array}{l}\text { Gestational age } \\
\text { at delivery }(\mathrm{w})\end{array}$ & $34.7(34.1-35.4)$ & $39.8(39.5-40.0)$ & $<0.001$ \\
\hline
\end{tabular}

difference $(P<0.05)$ in allele frequencies between patient and control groups.

The borderline allele association result regarding the exon $3 \mathrm{SNP}$, as well as the fact that there is evidence that analysis of two-loci haplotypes yields results that are occasionally more significant than those of single-locus tests, ${ }^{8}$ prompted us to use haplo type estimation analysis in evaluating the role of the EPHX gene in preeclampsia. Haplotype estimation analysis of exons 3 and 4 SNP genotype data by means of the maximum-likelihood method employing an expectation-maximization algorithm (EM) revealed that estimated pair of loci haplotype frequencies between the preeclampsia and control groups differed significantly $(P=0.02)$ (Table 3$)$. Moreover, according to single haplotype association analysis, the high activity haplotype T-A (Tyr113 - His139) was significantly overrepresented in the preeclampsia group $(P=0.01$; OR 1.61 (95\% CI: $1.12-2.32)$ ). To obtain unbiased estimates for the abovementioned exact test $P$ values, the Metropolis algorithm was used to analyse overall $(P=0.017 ; \mathrm{SE} \pm 0.003)$ and $\mathrm{T}-\mathrm{A}$ $(P=0.008 ; \mathrm{SE} \pm 0.001)$ haplotype contingency tables. In addition, power analysis was also applied to haplotype association analysis to evaluate whether the chromosome number used in the analysis was sufficient to detect a true positive association with preeclampsia. According to simulation analysis, approximately 370 chromosomes would be needed in each group for a statistically significant value (80\% power; $P<0.05$ ), calculated on the basis of the haplotype T-A odds ratio $(\mathrm{OR}=1.61)$. On the other hand, taking account of the $95 \%$ confidence intervals for the haplotype T-A odds ratio (1.12 to 2.32 ), it was estimated that the number of chromosomes needed would range from 140 (upper $\mathrm{OR}=2.32$ ) to 6000 (lower $\mathrm{OR}=1.12$ ) when the power limit is set at $80 \%$.

In order to study the extent of linkage disequilibrium (LD) between exons 3 and 4 loci, we performed pairwise LD analysis. Interestingly, pairwise LD analysis between exons 3 and 4 loci, which are located approximately $7 \mathrm{~kb}$ from each other, revealed stronger LD for all pairs of loci in the preeclampsia group $(P=0.03)$ than in the control group $(P=0.85)$. This result is consistent with the assumption that Finnish preeclampsia patients share a common genetic susceptibility background, and it shows that the LD between these two loci is reduced in both groups, which is probably a consequence of the extended physical distance $(\sim 7 \mathrm{~kb})$ between these loci.

\section{Discussion}

The familial nature of preeclampsia clearly indicates a significant genetic component, ${ }^{9,10}$ and this genetic component probably comprises multiple gene variants each contributing a small effect. ${ }^{11-18}$ In this study, the candidate gene was selected on the basis of the previously reported association between preeclampsia and $E P H X^{3}$, and tested for significance using single-point as well as haplotype asso- 
Table 2 Genotype and allele distributions of the EPHX gene among women with preeclampsia and healthy pregnant controls

\begin{tabular}{|c|c|c|c|c|}
\hline \multirow{2}{*}{ Exon 3} & \multicolumn{2}{|c|}{$\begin{array}{c}\text { Preeclampsia } \\
\text { group } \\
(\mathrm{n}=133)\end{array}$} & \multicolumn{2}{|c|}{$\begin{array}{c}\text { Control group } \\
(\mathrm{n}=115)\end{array}$} \\
\hline \multirow{2}{*}{\multicolumn{5}{|c|}{ Genotype frequencies }} \\
\hline & & & & \\
\hline TT (Tyr113Tyr113) & 76 & $57.1 \%$ & 52 & $45.2 \%$ \\
\hline TC (Tyr113His113) & 44 & $33.1 \%$ & 47 & $40.9 \%$ \\
\hline CC (His113His113) & 13 & $9.8 \%$ & 16 & $13.9 \%$ \\
\hline \multicolumn{5}{|l|}{ Allele frequencies } \\
\hline T (Tyr113) & 196 & $73.7 \%$ & 151 & $65.7 \%$ \\
\hline C (His113) & 70 & $26.3 \%$ & 79 & $34.3 \%$ \\
\hline \multicolumn{5}{|l|}{ Exon 4} \\
\hline \multicolumn{5}{|l|}{ Genotype frequencies } \\
\hline AA (His139His139) & 100 & $75.2 \%$ & 82 & $71.3 \%$ \\
\hline AG (His139Arg139) & 32 & $24.1 \%$ & 33 & $28.7 \%$ \\
\hline GG (Arg139Arg139) & 1 & $0.8 \%$ & - & $0 \%$ \\
\hline \multicolumn{5}{|l|}{ Allele frequencies } \\
\hline A (His139) & 232 & $87.2 \%$ & 197 & $85.7 \%$ \\
\hline G (Arg139) & 34 & $12.8 \%$ & 33 & $14.3 \%$ \\
\hline \multicolumn{5}{|c|}{$\begin{array}{l}\text { Asymptotic } P \text {-values for the exon } 3 \text { genotype and allele data: } \\
P=0.16 \text { and } P=0.05 \text {, respectively and for exon } 4 \text { genotype and } \\
\text { allele data: } P=0.47 \text { and } P=0.61 \text {. Both exons } 3 \text { and } 4 \text { polymorphisms } \\
\text { were found to be in Hardy-Weinberg equilibrium, both in the } \\
\text { preeclamptic and control groups. }\end{array}$} \\
\hline
\end{tabular}

Table 3 Estimated haplotype frequency distributions of $E P H X$ gene exons 3 and 4 polymorphisms in preeclamptic and control chromosomes

\begin{tabular}{|c|c|c|}
\hline \multirow[b]{2}{*}{ Haplotype } & \multicolumn{2}{|c|}{ Haplotype frequency $\pm S D^{\mathrm{a}}$} \\
\hline & $\begin{array}{l}\text { Preeclampsia } \\
\mathrm{n}=266\end{array}$ & $\begin{array}{l}\text { Controls } \\
n=230\end{array}$ \\
\hline T-A (Tyr113-His139) & $0.673 \pm 0.03$ & $0.561 \pm 0.03$ \\
\hline T-G (Tyr113-Arg139) & $0.064 \pm 0.02$ & $0.096 \pm 0.02$ \\
\hline C-A (His113-His139) & $0.199 \pm 0.03$ & $0.296 \pm 0.03$ \\
\hline C-G (His113-Arg139) & $0.064 \pm 0.02$ & $0.048 \pm 0.02$ \\
\hline
\end{tabular}

${ }^{a} n$ denotes to the number of chromosomes examined. Haplotype frequencies differed significantly ( $P=0.02$, Fisher's exact test) between preeclamptic and control groups.

ciation analyses with two intragenic SNPs. A borderline association was found between the $\mathrm{T}$ allele of the exon 3 SNP and preeclampsia and it was similar, although weaker than previously described. ${ }^{3}$ To further explore the association we undertook pair of loci haplotype estimation analysis, which involves the two SNP alleles, and we found that the haplotype T-A (Tyr113-His139) was significantly associated with preeclampsia. The validity of such an approach may be questioned, but predictions based on empirical data drawn from the literature currently support the feasibility of haplotype estimation analysis for detecting association more efficiently than single-point association analysis. ${ }^{8}$ The association between preeclampsia and haplotype T-A (Tyr113-His139) was apparent and this multipoint association may be of biological significance, since two SNPs in the coding region were used and both over-represented genetic variations result in an effect in the same direction, both increasing enzyme activity.

Any polymorphism is likely to make only a small individual contribution to the disease phenotype. A panel of two functional polymorphisms was required in the search for significant association in this study. The erosion of exons 3 and 4 inter-marker association as a result of recombination over generations was obvious according to the pairwise LD analysis. Therefore, it was preferable to use haplotype analysis to investigate the possible association between the disease and multiple SNPs before ruling out the candidate gene as contributing to preeclampsia. This also illustrates the difficulty that can be present in casecontrol association studies with negative results, where methodological flaws may compromise the validity of data, especially when $P$ values nearing significance are rejected and lead attention away from promising candidate genes. We have here shown that statistical analysis based on haplotypes can be more informative than multiple singlelocus tests.

Zusterzeel et al. also found a significant association between EPHX SNPs and preeclampsia, and in their study, tests for allelic associations between two SNPs, were conducted in their case and control groups separately. ${ }^{3}$ The tests were based on the multinomial probability of the two-locus genotype instead of a pair of single-locus genotypes. Based on a priori information linking the wildtype genotypes of the EPHX gene to high-activity phenotypes, they utilised predicted fast $v s$ slow combined genotypes and concluded that the high activity genotype combination was associated with preeclampsia. ${ }^{2}$ Another interesting finding was that SNP allele frequencies of the $E P H X$ gene vary considerably across human ethnic groups and populations. Frequencies in our populations were similar to those found in some other white populations, ${ }^{2,19,20}$ whereas in the Netherlands the population frequencies were similar to those of Chinese controls. ${ }^{3}$

In summary, the present data on Finnish women support the hypothesis that EPHX gene exon polymorphisms may be related to preeclampsia risk, as previously reported by Zusterzeel et $\mathrm{al}^{3}{ }^{3}$ The frequency of the haplotype T-A (Tyr113-His139) was significantly associated with preeclampsia, and this observation was in line with the results reported by Zusterzeel et al, suggesting that this particular haplotype may lead to an increased risk of preeclampsia. ${ }^{3}$ Further studies are called for to elucidate the influence of EPHX on the development of preeclampsia. 


\section{References}

1 Hartsfield Jr JK, Sutcliffe MJ, Everett ET, Hassett C, Omiecinski CJ, Saari JA: Assignment1 of microsomal epoxide hydrolase (EPHX1) to human chromosome 1q42.1by in situ hybridization. Cytogenet Cell Genet 1998; 83: 44-45.

2 Hassett C, Aicher L, Sidhu JS, Omiecinski CJ: Human microsomal epoxide hydrolase: genetic polymorphism and functional expression in vitro of amino acid variants. Hum Mol Genet 1994; 3: 421 428.

3 Zusterzeel PL, Peters WH, Visser W, Hermsen KJ, Roelofs HM, Steegers EA: A polymorphism in the gene for microsomal epoxide hydrolase is associated with pre-eclampsia. J Med Genet 2001; 38 $234-237$.

4 Wang X, Wang M, Niu T, Chen C, Xu X: Microsomal epoxide hydrolase polymorphism and risk of spontaneous abortion. Epidemiology 1998; 9: 540-544.

5 Lancaster JM, Brownlee HA, Bell DA et al: Microsomal epoxide hydrolase polymorphism as a risk factor for ovarian cancer. Mol Carcinog 1996; 17: 160-162.

6 Peltonen L, Jalanko A, Varilo T: Molecular genetics of the Finnish disease heritage. Hum Mol Genet 1999; 8: 1913-1923.

7 Report of the National High Blood Pressure Education Program Working Group on High Blood Pressure in Pregnancy: Am J Obstet Gynecol 2000; 183: S1-S22.

8 Martin ER, Lai EH, Gilbert JR et al: SNPing away at complex diseases: analysis of single-nucleotide polymorphismsaround APOE in Alzheimer disease. Am J Hum Genet 2000; 67: 383-394.

9 Arngrimsson R, Björnsson H, Geirsson R: Analysis of different inheritance patterns in preeclampsia/eclampsia syndrome. Hypertension in Pregnancy 1995; 14: 27 - 38.

10 Cincotta RB, Brennecke SP: Family history of pre-eclampsia as a predictor for pre-eclampsia in primigravidas. Int J Gynaecol Obstet 1998; 60: $23-37$.
11 Chen G, Wilson R, Boyd P et al: Normal superoxide dismutase (SOD) gene in pregnancy-induced hypertension: is the decreased SOD activity a secondary phenomenon? Free Radic Res 1994; 21 : $59-66$.

12 Ward K, Hata A, Jeunemaitre X et al: A molecular variant of angiotensinogen associated with preeclampsia. Nat Genet 1993; 4: 5961.

13 Dizon-Townson DS, Nelson LM, Easton K, Ward K: The factor V Leiden mutation may predispose women to severe preeclampsia. Am J Obstet Gynecol 1996; 175: $902-905$.

14 Sohda S, Arinami T, Hamada H, Yamada N, Hamaguchi H, Kubo T: Methylenetetrahydrofolate reductase polymorphism and preeclampsia. J Med Genet 1997; 34: 525-526.

15 Arngrimsson R, Sigurardottir S, Frigge ML et al: A genome-wide scan reveals a maternal susceptibility locus for pre-eclampsia on chromosome 2p13. Hum Mol Genet 1999; 8: 1799-1805.

16 Moses EK, Lade JA, Guo G et al : A genome scan in families from Australia and New Zealand confirms the presence of a maternal susceptibility locus for pre-eclampsia on chromosome 2. Am J Hum Genet 2000; 67: 1581-1585.

17 Arngrimsson R, Hayward C, Nadaud S: Evidence for a familial pregnancy-induced hypertension locus in the eNOS-gene region. Am J Hum Genet 1997; 61: 354-362.

18 Rinehart BK, Terrone DA, Lagoo-Deenadayalan S et al: Expression of the placental cytokines tumor necrosis factor alpha, interleukin 1 beta, and interleukin 10 is increased in preeclampsia. Am J Obstet Gynecol 1999; 181: 915 -920.

19 Smith CA, Harrison DJ: Association between polymorphism in gene for microsomal epoxide hydrolase andsusceptibility to emphysema. Lancet 1997; 350: 630-633.

20 Benhamou S, Reinikainen M, Bouchardy C, Dayer P, Hirvonen A: Association between lung cancer and microsomal epoxide hydrolase genotypes. Cancer Res 1998; 58: 5291-5293. 